\title{
Preparations for the modular distance learning (printed) amid the covid-19 pandemic: Assessment of public junior high school mathematics teachers' experiences
}

\author{
Richard J. Galano \\ galano.richard25.rg@gmail.com
}

\begin{abstract}
Since the start of community quarantines throughout the Philippines, schools have been forced to close their doors for face-to-face classes. The Department of Education, in its wish to continue delivering instruction, resorted to different distance learning delivery modalities - one of which is modular distance learning (printed). This study assessed the public junior high school mathematics teachers' experiences in preparing for the modular distance learning (printed) amid the COVID-19 pandemic. The descriptive correlational research design was used. The participants were 15 public junior high school mathematics teachers in Cagayan who used the modular approach in teaching in the first quarter of the school year 2020-2021. Results showed that the participants managed to be very prepared for the modular distance learning (printed) in mathematics before the formal opening of classes but circumstances were not easy for them as the learning modality required them to go through a difficult level of preparations. Furthermore, profile variables were compared and the levels of preparations and difficulty were correlated. An action plan based on the recommendations of the participants was presented.
\end{abstract}

Keywords: Covid-19 Pandemic; Modular Distance Learning; Preparations

\section{Introduction}

The COVID-19 pandemic has drastically altered the usual ways of doing things particularly the teaching and learning process that underwent a rapid transition from traditional to new normal. Due to the health threat of the pandemic, students are prohibited to go to school, and with that said, education is now brought in the comforts of their homes. The physical opening of schools will be determined by the Department of Health (DOH), the Inter-Agency Task Force (IATF) for the Management of Emerging Infectious Diseases in the Philippines, and the Office of the President on their risk severity grading or classification of a given community (Llego, 2020).

The Department of Education (DepEd) defined learning delivery modalities that schools may use based on their students' background as part of the learning continuity strategy for the school year 2020-2021. These are blended learning, distance learning, and home-schooling (“Ano ang pwedeng learning delivery modality?", 2020).

Llego (2020) gave his definition to each of the learning modalities:

1. Blended learning pairs face-to-face with any or a combination of online distance learning, modular distance learning, and TV/Radio-based Instruction;

2. Distance learning is a form of learning that takes place between a teacher and students who are geographically separated during the course of instruction; and 
3. Homeschooling is an Alternative Delivery Mode that seeks to provide students with basic education in a home-based environment, supported by trained parents, guardians, or tutors who have received appropriate training.

According to San Antonio (2020), the Undersecretary for Curriculum and Instruction, distance learning may be implemented through the following delivery modalities, namely Modular Distance Learning (Digital or Printed), Online Distance Learning, TV-Video (SLM-based or MELCs Mapped)/Radio-based Instruction, and Blended Distance Learning; of all the alternative learning modalities offered, most students prefer to use the "modular" distance learning option (Malipot, 2020). Along with modalities, he provided the following descriptions and considerations for modular distance learning:

1. A learner may adopt either Digital Modular Distance Learning (DMDL) or Printed Modular Distance Learning (PMDL). Learners with devices at home like laptop, desktop, or tablet, may adopt DMDL. The Self Learning Modules (SLMs) in different digital formats such as flat PDF, education videos, audio lessons, e-SLMs and others may be stored in a CD/DVD/USB flash drive/pen drive while the printed SLM shall be used by learners adopting PMDL.

2. Self-learning Modules which are K to 12 compliant are developed following the Alternative Delivery Mode Learning Resources Standards. The SLMs are designed to provide ample time for mastery and sufficient practice to ensure that the targeted most essential learning competencies are achieved. Clearly defined goals are attainable within the specific time frame by taking into consideration the learners' learning capacity based on their grade level.

3. Learners shall be provided with the suggested time frame to work on their assigned tasks. Flexibility in finishing each module is accorded to learners with respect to their learning needs, characteristics, and level of understanding to ensure that they have secured mastery of learning contents which is also an essential prerequisite for success in the succeeding modules.

4. Monitoring of learner progress and setting up of a feedback mechanism shall be ensured to help learners meet the most essential learning competencies while seeing the connection of one lesson to the next to reinforce the coherence of the curriculum.

5. Timely and appropriate monitoring and feedback for consultation and intervention purposes shall be put in place through various touch points such as text messaging, and audio/video calls, whichever is accessible to the learner. If possible and allowed, face-to-face interaction may be utilized for this purpose.

6. Members of the family and other stakeholders within the community who are trained as learning facilitators shall be engaged to provide learners with instructional support as needed in the absence of a classroom teacher. (San Antonio, 2020, p. 6)

In addition to the modules, learning activity sheets shall also be made available to the learners. Cariño (2020), Director of the DepEd Region 02, issued regional memorandum no. 42, s. 2020. She wrote:

1. Relative to the implementation of new normal for the incoming School Year 2020-2021, the Department of Education Region 02 through the Curriculum and Learning Management Division (CLMD) adopts the following guidelines in the preparation of Learning Activity Sheets (LAS) which shall be utilized by learnings during the home learning sessions.

2. Development of the LAS shall be based from the Most Essential Learning Competencies (MELC) issued by the Central Office.

3. Key stage 1 (Grades 1-3) learning areas shall be prepared by their own respective SDOs based on their MTB used as Methods of Teaching (MOT). Preparation of the Key Stage 2 (Grades 4-6), and Key Stage 3 (Junior HS) and Key Stage 4 (Senior HS) shall be based on the agreed distribution per grade levels. (Cariño, 2020, para. 1-3) 
The modular distance learning as the most preferred learning modality is now drawing different issues and concerns to the teachers. According to Malipot (2020):

The Teachers' Dignity Coalition (TDC), in a statement issued on July 6, claimed that among pressing concerns pointed out by teachers in the field is the need for them to create modules for the implementation of blended/distance learning when "specialists" from DepEd should be doing this. Education Secretary Leonor Briones said teachers are not being forced to create modules for their learners, admitting it is a "specialized kind of activity" that requires training.

In a separate news article, Malipot (2020) further reported:

Alliance of Concerned Teachers (ACT) Secretary General Raymond Basilio said that teachers are raising a "myriad of issues" with the modular learning preparations and expressed disappointment that while they have been tasked to make the activity sheets that will come with the modules, "they have not seen until today [August 4, 2020] the copies of these modules, forcing them to just base the activity sheets on last year's lessons." Basilio also pointed out that "reproduction cost is also a big problem as schools were forced to find ways to raise funds in so short time and some teachers are even being made to report to school as late as 11:00 pm in order to finish the printing on time.

DepEd is hopeful that schools can become less focused on written modules as a method of providing lessons remotely to pupils, citing high prices and a detrimental effect on the environment (Bernardo, 2020). Despite teachers' attempts to collect money, Secretary Briones urged the public not to give in to demands for cash donations for the ostensible production of self-learning modules (Magsino, 2020).

Teachers have been trying hard to follow the new guidelines set by DepEd in light of the new normal way of education. They must learn new skills to successfully carry out their duties and obligations in the absence of face-to-face lessons (Malipot, 2020). Unfortunately, emerging technology for distance learning is causing problems for the old teachers (ABS-CBN News, 2020).

In the delivery and retrieval of modules, concerned ROs and SDOs should "conduct disinfection of learning materials prior to packing and delivery" and form "stronger relationships with barangay councils that will assist in promoting the distribution and retrieval of modules to their respective barangays," according to DepEd Undersecretary Revsee Escobedo (Malipot, 2020).

As the timetable for the start of classes loomed closer on October 5, 2020, DepEd stepped up its arrangements (Featuresdesk (MD), 2020) but all of the students enrolled were not granted access to all of the learning modules. Since parents failed to pick up self-learning modules from schools, DepEd was still supplying them to students two days before classes began. (CNN Philippines Staff, 2020).

Hence, with the foregoing premises presented, the researcher embarked on this novel endeavor to assess the public junior high school mathematics teachers' experiences in preparing for the modular distance learning (printed) amid the COVID-19 pandemic to come up with recommendations-driven action plan for the improvement of the learning modality.

\subsection{Conceptual Framework}

The study sought to assess the public junior high school mathematics teachers' experiences in preparing for the modular distance learning (printed) amid the COVID-19 pandemic.

The profile of the participants, namely sex, length of service, and highest educational attainment was used for the purposes of comparing. The participants' assessments on the extent of their preparations and level of difficulty they experienced in preparing for modular distance learning (printed) were interpreted as indicators of their prevailing circumstances. 
On the other hand, the profile variables were looked into whether or not they caused significant differences in the participants' assessments. Moreover, a relationship between the participants' assessments on the extent of their preparations and level of difficulty they experienced in preparing was also tested if significant or not.

The output of the study was an action plan for the improvement of the modular distance learning (printed) in mathematics in public junior high school.

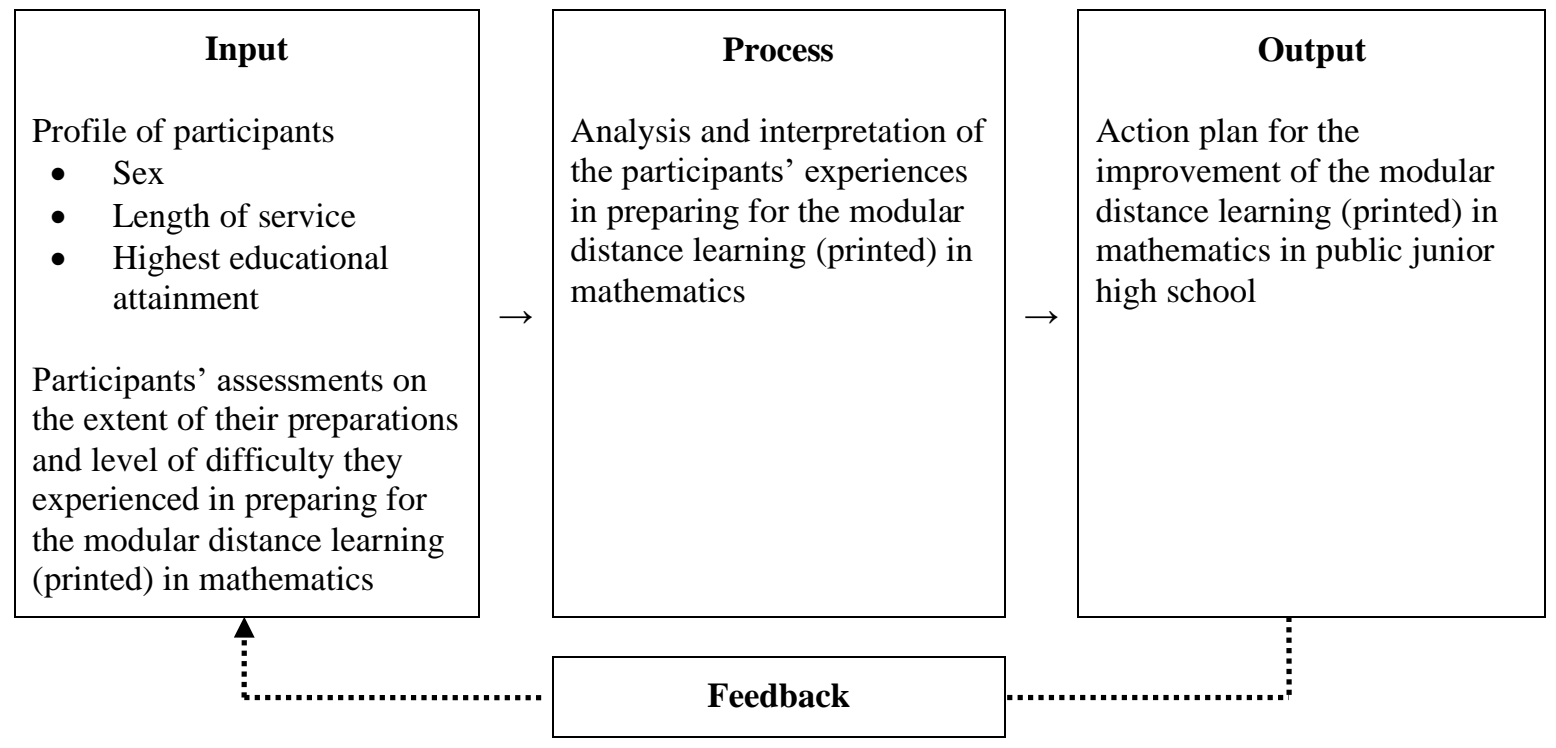

\subsection{Statement of the Problem}

The study sought to assess the public junior high school mathematics teachers' experiences in preparing for the modular distance learning (printed) amid the COVID-19 pandemic.

Specifically, it sought answers to the following:

1. What is the demographic profile of the participants in terms of the following variables:

1.1 Sex;

1.2 Length of service; and

1.3 Highest educational attainment?

2. What is the participants' extent of preparations for the modular distance learning (printed) in mathematics?

3. What is the participants' level of difficulty experienced in preparing for the modular distance learning (printed) in mathematics?

4. Is there a significant difference in the participants' assessment on the extent of their preparations for the modular distance learning (printed) in mathematics when grouped according to:

4.1 Sex;

4.2 Length of service; and

4.3 Highest educational attainment?

5. Is there a significant difference in the participants' assessment on the level of difficulty they experienced in preparing for the modular distance learning (printed) in mathematics when grouped according to: 
5.1 Sex;

5.2 Length of service; and

5.3 Highest educational attainment?

6. Is there a significant relationship between the participants' assessment on the extent of their preparations and level of difficulty they experienced in preparing for the modular distance learning (printed) in mathematics?

7. What are the participants' recommendations for the improvement of the modular distance learning (printed) in mathematics in public junior high school in terms of the following:

7.1 On Weekly Home Learning Plan (WHLP);

7.2 On modules;

7.3 On Learning Activity Sheets (LAS); and

7.4 On packaging, distribution, and retrieval of learning package?

8. What action plan can be done for the improvement of the modular distance learning (printed) in mathematics in public junior high school?

\section{Methodology}

\subsection{Research Design}

The study used the descriptive correlational research design. This method was used because the study sought to assess the public junior high school mathematics teachers' experiences in preparing for the modular distance learning (printed) amid the COVID-19 pandemic. The study was correlational since it also tested the differences in and the relationship between the participants' assessments on the extent of their preparations and level of difficulty they experienced in preparing for the modular distance learning (printed) in mathematics.

\subsection{Participants of the Study}

The participants of the study were 15 public junior high school mathematics teachers in Cagayan who used the modular approach in teaching in the first quarter of the school year 2020-2021. There was 1 participant from each of the following schools: Andarayan National High School, Aparri School of Arts and Trades, Baua National High School, Cabbo National High School, Cagayan National High School, Gadu National High School, Gonzaga National High School, Hacienda-Intal National High School, Imurung National High School, Matucay National High School, Rebecca National High School, Sanchez Mira School of Arts and Trades, Sta. Ana Fishery National High School, Tuao Vocational and Technical School, and Western Cagayan School of Arts and Trades.

\subsection{Instrumentation}

A non-standardized questionnaire was used as the sole instrument for data gathering. It was divided into 4 parts described as follows:

Part 1 - Collected the basic information of the participants: name (optional), sex, length of service, and highest educational attainment.

Part 2 - Assessed the participants' extent of preparations for the modular distance learning (printed) in mathematics. 
Part 3 - Assessed the participants' level of difficulty experienced in preparing for the modular distance learning (printed) in mathematics.

Part 4 - Collected the participants' recommendations for the improvement of the modular distance learning (printed) in mathematics in public junior high school.

\subsection{Data Gathering Procedure}

The researcher prepared a draft of the questionnaire with the help of 4 of his friends who are public junior high school mathematics teachers. The draft was submitted to 3 content experts ( 2 high school teachers and 1 college instructor) for validation for relevancy and all items were rated relevant. The validated questionnaire was translated into a google form and pre-tested to 3 teachers (1 TESDA and 1 college instructors and 1 elementary teacher) to ensure face validity. When the final draft of the questionnaire was made, the researcher began its administration. Participation in this study was completely voluntary and free from coercion. When all the participants were done answering the questionnaire, data were tabulated and analyzed using the Statistical Package for the Social Sciences (SPSS) software.

\subsection{Data Analysis}

The data gathered were treated using frequency count and percentage distribution, weighted mean, independent t-test, one-way analysis of variance (ANOVA), and Pearson correlation.

Frequency count and percentage distribution was used to present the profile of the participants. Weighted mean was used to determine the mean responses of the participants' assessments on the extent of their preparations and level of difficulty they experienced in preparing for the modular distance learning (printed) in mathematics.

To test for significant difference in the participants' assessment on the extent of their preparations for the modular approach in teaching, independent t-test was used when grouped according to sex and highest educational attainment and one-way ANOVA when grouped according to length of service.

To test for significant difference in the participants' assessment on the level of difficulty they experienced in preparing for the modular approach in teaching, independent $t$-test was used when grouped according to sex and highest educational attainment and one-way ANOVA when grouped according to length of service.

To test for significant relationship between the participants' assessments on the extent of their preparations and on level of difficulty they experienced in preparing for the modular approach in teaching mathematics, Pearson correlation was used.

The following scales were used to interpret the weighted means:

Table 1. Extent of Preparations for the Modular Approach in Teaching Mathematics

\begin{tabular}{ll}
\hline Range of Values & Qualitative Interpretation \\
\hline $4.20-5.00$ & Very High Extent \\
$3.40-4.19$ & High Extent \\
$2.60-3.39$ & Moderate Extent \\
$1.80-2.59$ & Low Extent \\
$1.00-1.79$ & Very Low Extent \\
\hline
\end{tabular}


Table 2. Level of Difficulty Experienced in Preparing for the Modular Approach in Teaching Mathematics

\begin{tabular}{ll}
\hline Range of Values & Qualitative Interpretation \\
\hline $4.20-5.00$ & Very Difficult \\
$3.40-4.19$ & Difficult \\
$2.60-3.39$ & Moderate \\
$1.80-2.59$ & Easy \\
$1.00-1.79$ & Very Easy \\
\hline
\end{tabular}

\section{Results and Discussion}

\subsection{Demographic Profile of Participants}

Table 3. Frequency and Percentage Distribution of the Participants' Sex

\begin{tabular}{lll}
\hline Sex & Frequency & Percentage \\
\hline Male & 7 & $47 \%$ \\
Female & 8 & $53 \%$ \\
Total & 15 & $100 \%$ \\
\hline
\end{tabular}

Table 3 shows that 7 or $47 \%$ of the participants are male while 8 or $53 \%$ are female. The figures imply that there are more female participants than that of the male.

Table 4. Frequency and Percentage Distribution of the Participants' Length of Service

\begin{tabular}{lll}
\hline Length of Service & Frequency & Percentage \\
\hline 0 to 2 years & 7 & $47 \%$ \\
3 to 5 years & 5 & $33 \%$ \\
6 years or more & 3 & $20 \%$ \\
Total & 15 & $100 \%$ \\
\hline
\end{tabular}

Table 4 shows that 7 or $47 \%$ of the participants have been teaching for 0 to 2 years while 5 or $33 \%$ and 3 or $20 \%$ are for 3 to 5 years and 6 years or more, respectively. The figures imply that most of the participants have been teaching for less than 3 years.

Table 5. Frequency and Percentage Distribution of the Participants' Highest Educational Attainment

\begin{tabular}{lll}
\hline Highest Educational Attainment & Frequency & Percentage \\
\hline Bachelor's Degree & 5 & $33 \%$ \\
Master's Degree & 10 & $67 \%$ \\
Total & 15 & $100 \%$ \\
\hline
\end{tabular}


Table 5 shows that 5 or $33 \%$ of the participants are holders of bachelor's degree while 10 or $67 \%$ are master's degree. The figures imply that more participants are master's degree holders.

3.2 Participants' Assessment on the Extent of Their Preparations for the Modular Distance Learning (Printed) in Mathematics

Table 6. Mean Response of the Participants' Assessment on the Extent of Their Preparations for the Modular Distance Learning (Printed) in Mathematics

\begin{tabular}{lll}
\hline Preparation & Mean & Description \\
\hline On Weekly Home Learning Plan (WHLP) & 4.40 & Very High Extent \\
On Modules & 4.24 & Very High Extent \\
On Learning Activity Sheets (LAS) & 4.48 & Very High Extent \\
On Packaging, Distribution, and Retrieval of Learning Package & 4.72 & Very High Extent \\
Grand Mean & 4.46 & Very High Extent \\
\hline
\end{tabular}

Table 6 shows that the participants' assessments on the extent of their preparations on Weekly Home Learning Plan (WHLP), modules, Learning Activity Sheets (LAS), and packaging, distribution, and retrieval of learning package were all in very high extent. Generally, the participants' assessment on the extent of their preparations for the modular distance learning (printed) in mathematics was in very high extent most specially on packaging, distribution, and retrieval of learning package. This result is consistent with the DepEd's effort to strengthen its rigorous preparations for SY 2020-2021 (Featuresdesk (MD), 2020).

\subsection{Participants' Assessment on the Level of Difficulty They Experienced in Preparing for the Modular} Distance Learning (Printed) in Mathematics

Table 7. Mean Response of the Participants' Assessment on the Level of Difficulty They Experienced in Preparing for the Modular Distance Learning (Printed) in Mathematics

\begin{tabular}{lll}
\hline Difficulty & Mean & Description \\
\hline On Weekly Home Learning Plan (WHLP) & 3.99 & Difficult \\
On Modules & 3.87 & Difficult \\
On Learning Activity Sheets (LAS) & 4.18 & Difficult \\
On Packaging, Distribution, and Retrieval of Learning Package & 4.16 & Difficult \\
Grand Mean & 4.05 & Difficult \\
\hline
\end{tabular}

Table 7 shows that the participants' assessments on the level of difficulty they experienced in preparing on Weekly Home Learning Plan (WHLP), modules, Learning Activity Sheets (LAS), and packaging, distribution, and retrieval of learning package were all difficult. Generally, the participants' assessment on the level of difficulty they experienced in preparing for the modular distance learning (printed) in mathematics was difficult most specially on LAS. This result is an implication of the fact that teachers were raising a "myriad of issues" with the modular learning preparations (Malipot, 2020). 
3.4 Test for Significant Difference in the Participants' Assessment on the Extent of Their Preparations for the Modular Distance Learning (Printed) in Mathematics

Table 8. T-test Result to Test for Significant Difference in the Participants' Assessment on the Extent of Their Preparations for the Modular Distance Learning (Printed) in Mathematics Grouped According to Sex

\begin{tabular}{llll}
\hline Grouping Variable & t-Statistic & p-Value & Decision \\
\hline Sex & 2.19 & 0.048 & Reject $\mathrm{H}_{0}$ \\
\hline
\end{tabular}

Table 8 shows that the t-test result has a p-value (0.048) that is less than 0.05 . This implies that there is a significant difference in the participants' assessment on the extent of their preparations for the modular distance learning (printed) in mathematics when grouped according to sex. Furthermore, the male participants tend to have higher appraisal on the extent of their preparations than that of the female.

Table 9. One-way ANOVA Test Result to Test for Significant Difference in the Participants' Assessment on the Extent of Their Preparations for the Modular Distance Learning (Printed) in Mathematics Grouped According to Length of Service

\begin{tabular}{llll}
\hline Grouping Variable & F-Statistic & p-Value & Decision \\
\hline Length of Service & 2.49 & 0.125 & Accept $\mathrm{H}_{0}$ \\
\hline
\end{tabular}

Table 9 shows that the one-way ANOVA test result has a p-value (0.125) that is greater than 0.05 . This implies that there is no significant difference in the participants' assessment on the extent of their preparations for the modular distance learning (printed) in mathematics when grouped according to length of service. Furthermore, the participants' appraisal on the extent of their preparations was regardless of length of service.

Table 10. T-test Result to Test for Significant Difference in the Participants' Assessment on the Extent of Their Preparations for the Modular Distance Learning (Printed) in Mathematics Grouped According to Highest Educational Attainment

\begin{tabular}{llll}
\hline Grouping Variable & t-Statistic & p-Value & Decision \\
\hline Highest Educational Attainment & -0.07 & 0.944 & Accept $\mathrm{H}_{0}$ \\
\hline
\end{tabular}

Table 10 shows that the t-test result has a p-value (0.944) that is greater than 0.05 . This implies that there is no significant difference in the participants' assessment on the extent of their preparations for the modular distance learning (printed) in mathematics when grouped according to highest educational attainment. Furthermore, the participants' appraisal on the extent of their preparations was regardless of highest educational attainment.

3.5 Test for Significant Difference in the Participants' Assessment on the Level of Difficulty They Experienced in Preparing for the Modular Distance Learning (Printed) in Mathematics

Table 11. T-test Result to Test for Significant Difference in the Participants' Assessment on the Level of Difficulty They Experienced in Preparing for the Modular Distance Learning (Printed) in Mathematics Grouped According to Sex

\begin{tabular}{llll}
\hline Grouping Variable & t-Statistic & p-Value & Decision \\
\hline Sex & 1.51 & 0.156 & Accept $\mathrm{H}_{0}$ \\
\hline
\end{tabular}


Table 11 shows that the t-test result has a p-value $(0.156)$ that is greater than 0.05 . This implies that there is no significant difference in the participants' assessment on the level of difficulty they experienced in preparing for the modular distance learning (printed) in mathematics when grouped according to sex. Furthermore, the participants' appraisal on the level of difficulty they experienced was regardless of sex.

Table 12. One-way ANOVA Test Result to Test for Significant Difference in the Participants' Assessment on the Level of Difficulty They Experienced in Preparing for the Modular Distance Learning (Printed) in Mathematics Grouped According to Length of Service

\begin{tabular}{llll}
\hline Grouping Variable & F-Statistic & $\mathrm{p}$-Value & Decision \\
\hline Length of Service & 0.63 & 0.551 & Accept $\mathrm{H}_{0}$ \\
\hline
\end{tabular}

Table 12 shows that the one-way ANOVA test result has a p-value (0.551) that is greater than 0.05 . This implies that there is no significant difference in the participants' assessment on the level of difficulty they experienced in preparing for the modular distance learning (printed) in mathematics when grouped according to length of service. Furthermore, the participants' appraisal on the level of difficulty they experienced was regardless of length of service.

Table 13. T-test Result to Test for Significant Difference in the Participants' Assessment on the Level of Difficulty They Experienced in Preparing for the Modular Distance Learning (Printed) in Mathematics Grouped According to Highest Educational Attainment

\begin{tabular}{llll}
\hline Grouping Variable & $\mathrm{t}$-Statistic & $\mathrm{p}$-Value & Decision \\
\hline Highest Educational Attainment & 0.85 & 0.409 & Accept $\mathrm{H}_{0}$ \\
\hline
\end{tabular}

Table 13 shows that the t-test result has a p-value (0.409) that is greater than 0.05 . This implies that there is no significant difference in the participants' assessment on the level of difficulty they experienced in preparing for the modular distance learning (printed) in mathematics when grouped according to highest educational attainment. Furthermore, the participants' appraisal on the level of difficulty they experienced was regardless of highest educational attainment.

3.6 Test for Significant Relationship between the Participants' Assessments on the Extent of Their Preparations and Level of Difficulty They Experienced in Preparing for the Modular Distance Learning (Printed) in Mathematics

Table 14. Correlations Test Result to Test for Significant Relationship between the Participants' Assessments on the Extent of Their Preparations and Level of Difficulty They Experienced in Preparing for the Modular Distance Learning (Printed) in Mathematics

\begin{tabular}{llll}
\hline Variables & Pearson's r & p-Value & Decision \\
\hline $\begin{array}{l}\text { Participants' Assessments on the Extent of Their } \\
\text { Preparations and Level of Difficulty They }\end{array}$ & 0.54 & 0.045 & Reject $\mathrm{H}_{0}$ \\
Experienced & & & \\
\hline
\end{tabular}

Table 14 shows that the correlations test result has a p-value (0.045) that is less than 0.05 . This implies that there is a significant relationship between the participants' assessments on the extent of their preparations and level of difficulty they experienced in preparing for the modular distance learning (printed) in mathematics. Furthermore, the Pearson's r (0.54) indicates that there is a strong positive correlation between 
the variables, that is, the higher is the participants' assessment on the extent of their preparations, the higher is their assessment on the level of difficulty they experienced.

\subsection{Participants' Recommendations for the Improvement of the Modular Distance Learning (Printed) in Mathematics in Public Junior High School}

The following recommendations were given by the participants to improve the modular distance learning (printed) in mathematics in public junior high school in terms of the following:

a. On Weekly Home Learning Plan (WHLP)

- In the development of Weekly Home Learning Plan (WHLP), the flow of the Most Essential Learning Competencies (MELCs) should be mastered and competencies that were merged, dropped, and retained should be identified. Teachers of the same subject matter including the parents or guardians should collaborate. Practice time management to have more time to prepare. Lessen the number of activities and follow the general format. Technical Assistance should also be provided to teachers and the conduct of Learning Action Cell (LAC) session is recommended.

- In the quality assurance of WHLP, it should be done by the subject coordinators, head teachers or master teachers, or assigned committee. Its alignment with the Learning Activity Sheets (LAS) or modules should be checked. There should be ample time to do the quality assurance.

- In the reproduction of WHLP, there should be sufficient budget for printing materials like bond paper, ink and specially printer. Schools should purchase Riso machines for faster reproduction. WHLP should be reproduced before the LAS or modules to serve as guide in printing. There should be more time for reproduction.

- In the sorting of WHLP, teachers should collaborate and work together. It should be planned and organized, and done per grade level or by color-coding. WHLP should be sorted out with the modules and teachers, with the assistance of administrative aides, must be given enough time to do it.

- In the communication of WHLP to parents or guardians, it should be done clearly and properly. Preferably, use online platform to lessen the use of papers. Standards of electronic communication should be specific such as in texts, calls, or chats. Students should also be given a copy of WHLP.

- In the orientation of parents or guardians of the WHLP, teachers should be knowledgeable enough to answer queries especially regarding the delivery modality. Orientation can be virtual or through phone call, but face-to-face most of the time because there are parents or guardians who do not have gadgets. It should be done in mother tongue to ensure understanding. Schedule of orientation must be made known earlier to all parents or guardians.

b. On modules

- In the quality assurance of modules, it should be done amply in school-based with the assistance of the school head or a content expert. Subject teachers must go over the modules to check for possible errors like answer keys or links before reproduction.

- In the reproduction of modules, it could be done monthly to avoid too much contact with other people. It must be readable and well-printed and should not be in booklet type. There should be more manpower and printing materials like printers, photocopiers, and bond papers. Schools should be given sufficient funds for reproduction and they should purchase Riso machines.

- In the sorting of modules, it should be done systematically, such as per subject, and teachers should work together with the help of administrative aides. Double check what should be sorted and, after sorting, assure that the pages are consecutive. Time management is necessary in sorting modules before the distribution. 
c. On Learning Activity Sheets (LAS)

- In the development of Learning Activity Sheets (LAS), it should be done amply and given ahead of time by the assigned content writers so that teachers can also review if there are some errors. The focus of LAS should be on the competencies least mastered by the students. Include appropriate learning activities about students' prior knowledge but minimize the number of activities and items.

- In the quality assurance of LAS, it should be done amply in school-based by subject coordinators, master teachers or head teachers. Answer keys and links should be checked for the learners.

- In the reproduction of LAS, there should be enough fund to cater all the learners with 1:1 ratio but LAS should not be in booklet type. There should be more printing materials like printers, photocopiers, and bond papers and schools should purchase Riso machines. LAS can be reproduced as an alternative to modules.

- In the sorting of LAS, it should be systematic and teachers should work together with the help of administrative aides. Double check what should be sorted and, after sorting, assure that the pages are complete. Time management is necessary.

d. On packaging, distribution, and retrieval of learning package

- In packaging the modules and Learning Activity Sheets (LAS), it must be well-done per advisory class with a checklist and schedule of the learners. Assign an envelope, preferably color-coded per year level, to each learner properly labeled with his or her name, address, and school. Secure the modules in a big box to facilitate distribution and retrieval.

- In communicating the schedule of distribution and retrieval of learning package, parents, students, and barangay officials should be informed in person or through texts, calls, or chats. For parents who do not have cellphones or signal or live in far-flung areas, they should be informed face-to-face. Learners agreement form and guidelines on the distribution and retrieval of learning package must be informed ahead of time.

- In facilitating the distribution and retrieval of learning package, assign teacher in each barangay feeder of the school to facilitate the distribution and retrieval of learning package. Barangay officials must help and ensure that health protocols are strictly observed. Monitoring tool should be prepared for tracing distributed and retrieved modules.

3.8 Action Plan for the Improvement of the Modular Distance Learning (Printed) in Mathematics in Public Junior High School

Table 15. Action Plan for the Improvement of the Modular Distance Learning (Printed) in Mathematics in Public Junior High School

\begin{tabular}{llll}
\hline Objective & Task & Persons Responsible & Due \\
\hline $\begin{array}{l}\text { Come up with a set of Weekly } \\
\text { Home Learning Plan (WHLP) for } \\
\text { one entire quarter }\end{array}$ & $\begin{array}{l}\text { Collaborate with other subject area teachers } \\
\text { and integrate all subjects in one learning plan }\end{array}$ & Mathematics Teachers & $\begin{array}{l}\text { After the development } \\
\text { of WHLP }\end{array}$ \\
$\begin{array}{l}\text { Orient parents or guardians on the } \\
\text { WHLP }\end{array}$ & $\begin{array}{l}\text { Conduct orientation of parents or guardians } \\
\text { on the WHLP in face-to-face or virtual and } \\
\text { in an assembly or small groups }\end{array}$ & $\begin{array}{l}\text { Mathematics Teachers } \\
\text { and School Principals }\end{array}$ & $\begin{array}{l}\text { Before the distribution } \\
\text { of learning package }\end{array}$ \\
$\begin{array}{l}\text { Minimize the number of activities } \\
\text { per lesson or number of items per } \\
\text { activity }\end{array}$ & $\begin{array}{l}\text { Choose the most appropriate learning } \\
\text { activities according to students' capacity }\end{array}$ & Mathematics Teachers & $\begin{array}{l}\text { Before the finalization } \\
\text { of WHLP }\end{array}$ \\
$\begin{array}{l}\text { Assure quality of WHLP, modules, } \\
\text { and Learning Activity Sheets } \\
\text { (LAS) }\end{array}$ & $\begin{array}{l}\text { Assign a committee to do the quality } \\
\text { assurance of WHLP, modules, and LAS }\end{array}$ & School Principals & $\begin{array}{l}\text { Before the finalization } \\
\text { of WHLP, modules, } \\
\text { and LAS }\end{array}$
\end{tabular}


Reproduce WHLP, modules, and LAS efficiently and effectively

Sort WHLP, modules, and LAS efficiently and effectively

Package properly the modules and LAS

Inform the parents or guardians of the schedule of distribution and retrieval of learning package

Facilitate the distribution and retrieval of learning package
Procure additional printers or photocopiers preferably Riso and sufficient reams of bond paper and bottles of ink

Increase manpower in reproduction of WHLP, modules, and LAS by requiring administrative aides to assist

Increase manpower in sorting of WHLP, modules, and LAS by requiring

administrative aides to assist

Assign an envelope to each learner with color-coding system and properly label with his or her name, parent's or guardian's name and contact number, and address.

Come up with a schedule of the distribution and retrieval of learning package for one entire quarter

Ask for the assistance of the barangay officials in the distribution and retrieval of learning package
School Principals

At least a day before the finalization of WHLP, modules, and LAS

School Principals

After the reproduction of WHLP, modules, and LAS

School Principals After the sorting of WHLP, modules, and LAS

School Principals and

Before the packaging of modules and LAS

School Principals

Before the first distribution of learning package

School Principals Before the distribution of learning package

\section{Conclusion}

The emergence of COVID-19 as a global pandemic has drastically changed the way education is delivered from traditional to new normal. The Department of Education (DepEd), in its desire to continue education even in times of crisis, identified different distance learning delivery modalities that schools may adopt to still be able to operate despite the imposition of community quarantines by the Philippine government. Of all the options, the modular distance learning happened to be the preferred modality by most of the students.

This study was conducted to assess the public junior high school mathematics teachers' experiences in preparing for the modular distance learning (printed) amid the COVID-19 pandemic. Given that the modality is a new readjustment in the basic education system, result showed that the participants managed to be very prepared for the modular distance learning (printed) in mathematics before the formal opening of classes for School Year 2020-2021. However, circumstances were not easy for them as the learning modality required them to go through a difficult level of preparations.

DepEd Secretary Briones had said that the opening of classes was generally very successful and result of this study implies her claim based on the very high extent of participants' preparations for the modular distance learning (printed) in mathematics. Nonetheless, with some recommendations offered by the participants, the modular distance learning (printed) still has rooms for improvement.

As distance education continues amid the COVID-19 pandemic, the researcher hopes that this study will contribute to the overall improvement of the modular distance learning (printed) in mathematics in public junior high school particularly in Cagayan. Above all, continuous improvement of the learning modality is necessary until the desirable combination of school practices is reached. Improvement in the temporary education system requires change and so every stakeholder must be willing to compromise. 


\section{Recommendations}

In the light of the findings and conclusions, the researcher hereby offers the following recommendations:

The public junior high school mathematics teachers may sustain their extent of preparations for the modular distance learning (printed) particularly on Weekly Home Learning Plan (WHLP), modules, Learning Activity Sheets (LAS), and packaging, distribution, and retrieval of learning package.

The public junior high school mathematics teachers and their school principals may adopt and contextualize the action plan and incorporate it in their school operations and timeline. The plan can help the schools to have better and smoother preparations for the modular distance learning by orienting them towards a "time is gold" mentality.

The public secondary school principals may conduct a diagnostic assessment focusing on the difficulties experienced by their mathematics teachers in preparing for the modular approach in teaching particularly on Weekly Home Learning Plan (WHLP), modules, Learning Activity Sheets (LAS), and packaging, distribution, and retrieval of learning package to come up with specific solutions.

The same study maybe conducted with a larger sample size to include the many other public junior high schools in Cagayan that were not part of this study.

\section{References}

ABS-CBN News. (2020). Elderly teachers in PH struggling with new technology for distance learning. ABS-CBN News. https://news.abs-cbn.com/video/spotlight/10/03/20/elderly-teachers-in-ph-struggling-with-new-technology-for-distance-learning

Ano ang pwedeng learning delivery modality? (2020). Department of Education. https://www.deped.gov.ph/2020/07/22/ano-angpwedeng-learning-delivery-modality/

Bernardo, J. (2020). Citing costs, DepEd says schools should rely less on printed modules for distance learning. ABS-CBN News. https://news.abs-cbn.com/news/09/10/20/citing-costs-deped-says-schools-should-rely-less-on-printed-modules-for-distance-learning

Burge, A. (n.d.). How to design effective teaching modules. UACES. https://www.uaces.org/resources/articles/how-design-effectiveteaching-modules

Cariño, E. L. (2020). Instructions and timelines in the preparation of learning activity sheets (LAS). GOVPH. http://region2.deped.gov.ph/rm-42-s-2020-instructions-and-timelines-in-the-preparation-of-learning-activity-sheets-las/

CNN Philippines Staff. (2020). DepEd conducts last-minute distribution of self-learning modules. CNN Philippines. https://www.cnn.ph/news/2020/10/3/DepEd-module-distribution.html

Featuresdesk (MD). (2020). DepEd strengthens preparations for distance learning with dry-run simulation. PAGEONE. http://pageone.ph/deped-strengthens-preparations-for-distance-learning-with-dry-run-simulations/

Llego, M. A. (2020). DepEd learning delivery modalities for school year 2020-2021. TeacherPH. https://www.teacherph.com/depedlearning-delivery-modalities/

Magsambol, B. (2020). 3 weeks into school opening, teachers say they still don't have copies of learning modules. Rappler. https://www.rappler.com/nation/teacher-say-they-don't-have-copies-learning-modules-weeks-school-opening-august-2020

Magsino, D. (2020). DepEd's Briones warns vs solicitations for self-learning modules. GMA News Online. https://www.gmanetwork.com/news/news/nation/757246/deped-s-briones-warns-vs-solicitations-for-self-learning-modules/story/

Malipot, M. H. (2020). DepEd assures safety protocols in place in delivery of self-learning modules. Manila Bulletin. https://mb.com.ph/2020/08/29/deped-assures-safety-protocols-in-place-in-delivery-of-self-learning-modules/

Malipot, M. H. (2020). DepEd: Most students prefer 'modular' learning over online. Manila Bulletin. https://mb.com.ph/2020/07/03/deped-most-students-prefer-modular-learning-over-online/

Malipot, M. H. (2020). Filipino teachers go beyond the call of duty. Manila Bulletin. https://mb.com.ph/2020/10/05/ filipino-teachers-gobeyond-the-call-of-duty/

Malipot, M. H. (2020). Teachers air problems on modular learning system. Manila Bulletin. https://mb.com.ph/2020/08/04/ teachers-airproblems-on-modular-learning-system/

Malipot, M. H. (2020). Teachers' participation in module-writing for blended learning 'crucial' - DepEd. Manila Bulletin. https://mb.com.ph/2020/07/11/teachers-participation-in-module-writing-for-blended-learning-crucial-deped/

San Antonio, D. M. (2020). Suggested strategies in implementing distance learning delivery modalities (dldm) for school year $2020-2021$ [Memorandum]. Department of Education. https://depedmandaluyong.files.wordpress.com/2020/07/dm-ci-2020-00162_suggestedstrategies-on-dldm-fy-2020-2021.pdf

Torres, C. (2020). What is a teacher's role in "the new normal"? ASCD In Service. https://inservice.ascd.org/what-is-a- teachers- role-inthe-new-normal-pandemic/ 